\title{
METHODOLOGY OF SELECTING STRATEGIES FOR UNDERWATER EXPLORATION CONDUCTED FOR THE PURPOSES OF LITIGATION - PLACES AND CONDITIONS FOR THE EXPLORATION
}

Adam Olejnik, Roman Szymański

Department of Underwater Works Technology in Gdynia, Polish Naval Academy Poland

\section{ABSTRACT}

This is the first publication from a series of articles devoted to the issues of underwater exploration carried out for litigation purposes. The present paper suggests that an exploration strategy should be defined as: all actions that aim at creating and implementing a plan of exploration, conducted with the application of a defined exploration methodology - here understood to refer to the technical way the task is completed. Such an approach is taken in order to ensure the most adequate involvement of means and resources for the plan's implementation. Since the choice of strategy affects many aspects that range from the technical to the environmental, this first part focuses on the location of the exploration and the anticipated conditions. Key words: underwater technology, underwater prospecting, marine engineering.

ARTICLE INFO

PolHypRes 2015 Vol. 52 Issue 3 pp. 29-34

ISSN: $1734-7009$ elSSN: 2084-0535

DOI: $10.1515 /$ phr-2015-0014

Pages: 6, figures: 0 , tables: 0

page www of the periodical: www.phr.net.pl

Publisher

Polish Hyperbaric Medicine and Technology Society
Rewiev article

Delivery date: $15.06 .2015 \mathrm{r}$.

Date of approval for print: $29.07 .2015 \mathrm{r}$ 


\section{INTRODUCTION}

Underwater exploration conducted for litigation purposes may be divided into two types of tasks. In the first case exploration may be conducted in order to find an underwater humanoid object [1], [2], i.e. the corpse of a victim which had been prepared in such a way as to remain underwater and not resurface, with the aim of concealing the fact of committing a crime.

The second type of task involves searching for submerged objects, which in litigation serve as evidence corroborating the course of events that had been reconstructed during the investigation, or primary evidence that was directly related to the investigated criminal activity. This type of task most frequently involves searching for a weapon (or its component parts) that had been used to commit a criminal act. Regardless of its type, the task will always involve finding an object (determining the location) and recovering it to the surface. This follows from the fact that on account of the principle of direct examination of evidence by a judge, a judicial body's decision should be particularly based on primary evidence in criminal proceedings.

The effectiveness of the implementation of such tasks is affected by many factors, from organisational and technical, to environmental. The impact of each of the factors is diverse and very often unrelated to the synergic effect. Hence the need to rationalise the approach to this task through the creation of exploration strategies. However, it is important to note the difference between an exploration strategy and methodology.

Exploration strategy is here understood as the creation and implementation of a plan of exploration with the use of a specific methodology, i.e. a technical way to implement a task. In such an approach, submarine exploration for litigation purposes will consist of the creation of a search plan based on the place of planned exploration (the analysis of the body of water and its surroundings), the object being searched for and the selection of available methods for the technical implementation of the exploration. Such an approach ensures by far the most adequate selection of means and resources for the implementation of the task in hand.

\section{Place OF EXPLORATION}

Reconnaissance of the place of operations and a detailed narrowing of the explored area is essential for time, expenses, and, most importantly, chances of success. The place of exploration is often determined on the basis of witnesses' statements and rarely on the basis of the data from navigational devices. If we are in possession of such data, they have been obtained following the cooperation of the accused with the competent authorities or as a result of witness interrogation. However, a common problem is that a long time has very often passed since the primary activity (sinking of a body in order to conceal the crime).

Selection of the area to be explored is influenced by many factors, the passage of time being one of them [4]; possible changes to the topography, shore of the lake, landscape architecture, all of which might have occurred over time being the reason for this consideration. The accused will be very eager to provide any information that might contribute to the commutation of his sentence or end in a trial based on circumstantial evidence, but he will hardly ever be interested in a full corroboration of his testimony. In fact, the less successful the exploration, the more secure his position during the trial, at least from his point of view. He will not be interested in the perspective of a successful exploration, unless the recovery of the underwater object is to prove his innocence. However, the authors' experience includes cases where the accused testified that his orientation in the area during the primary activity was based on the glade in the forest, or mistletoe on the trees growing along the lake shore, whereas in fact the glade appeared a few years after the events in question.

The mistletoes, on the other hand, cannot be seen from the place indicated as the location where the body was disposed of, especially during the night (time of the occurrence). Certainly, such testimony can be easily verified during the on-site visit with the suspect to see how good his orientation is at different times of the day and night and whether he is capable of pointing to the same spot at the surface of the body of water. Even if a fair amount of information can be ascertained, it will still be approximate and the area of exploration might still be quite vast. In such a case bathymetric, hydrological and meteorological data should come in useful.

For instance, information as to whether the lake is a flow-through body of water and data on the direction of the most frequent winds allows the evaluation of how far the boat/dinghy might have drifted at the time when the suspect was sinking the object that is now being searched for. It is also important to know whether any type of vessel was used to aid the disposal of the object, or whether it was thrown into the water from the shore. It is only when all the information is added up that the determination of a plausible spot of the objects is possible.

What is important is that the exploration should not be limited to the area determined in such a manner. In accordance to good practice, this place should be understood as the centre of the exploration area with a radius that is dependent on its size. In extreme cases, when it is not possible to make an accurate assessment of the precise area of the body of water where the search for the object should begin, a search of the entire body of water should be decided on, regardless of its size obviously only when there are reasons to assume that the object is in this particular body of water.

\section{CONDITIONS FOR EXPLORATION}

In the present paper, the characteristics of bodies of sea water have been intentionally omitted since a vast majority of the issues discussed refers to inland water basins.

The cold and not very transparent waters of Polish basins and inland waterways, typical of temperate climate, are not conducive for exploration activities. Industrial pollution, deoxygenation, and most importantly eutrophication caused by fertilizers washed down from fields that lead to the development of algae and silting additionally affect visibility.

Most Polish lakes are eutrophic, with little clarity and low depth. Only mountain lakes and sparse, usually deep oligotrophic glacial lakes have the clarity of a few, or less frequently more than ten metres. Horizontal visibility near the surface of the lake (epilimnion) rarely exceeds two metres and usually arrives at a few dozen 
centimetres; the situation is slightly better in hypolimnion, where in deeper lakes visibility can reach a few, and in rare cases more than ten metres. Depending on the angle of incidence, the light arriving at the surface of water is partially or entirely reflected. The sun's rays that do reach the water are absorbed and diffused [5]. If diffusion is generally responsible for about 3\% of light, then absorption causes the lack of light at the depth of a few, or more than ten metres on account of the presence of particles of organic matter, suspension and water particles themselves. Slightly less importance is attributed to the colour of water and the vertical shore shape of a body of water [3].

Smaller, shallower bodies of water (astatic reservoirs, ponds etc.) which formed both naturally and as a result of human activity (clay pits, open pits, peat pits) are in majority characterised by a very low water clarity. Only those that were located on a rocky or sandy ground e.g. flooded quarries have crystal clear water and a considerable depth. This group should include some oxbows [6].

Another group of reservoirs is constituted by dam reservoirs which combine the characteristics of lakes with the characteristics of rivers that make up the reservoir itself. In the case of smaller reservoirs on typically mountain streams located on rocky ground, water clarity may be similar to that of mountain lakes. However, in most cases they are wide reservoirs with the characteristics of eutrophic lakes additionally supplied with water for rivers with high amount of suspension. It is important to understand when considering the issue of searching for objects located at the bottom of a reservoir that except for mountain and oligotrophic lakes, the basin is typically filled with a layer of sediment (silt) a few meters deep that is disturbed by even the slightest movements of water.

Rivers are yet another type of an inland body of water in which searches are conducted. An average flow velocity in Polish lowland rivers comes to about $1 \mathrm{~m} / \mathrm{s}$, and it only rises significantly during floods. It is however an average value that essentially depends on the inclination of the land and the mass of flowing water. Hence we have nearly static meandering rivers such as the Biebrza and fast flowing ones like the Oder.

The flow velocity measured at the river bed is not even either;it may be twice the average speed in a given place when measured in rapids. Polish rivers are predominantly shallow; their depth is basically no more than 6 - 8 metres with rapid changes. In the water column, suspended organic and inorganic material can be found (floating), whereas dragged material is more likely to be seen nearer the bottom. These items are the decisive factors behind the clarity of water which, with the exception of mountain rivers and single stretches of lowland rivers, reduce visibility to ten centimetres or less [6].

The last group of inland reservoirs is constituted by artificial watercourses. They include canals and drainage ditches. Canals (e.g. canals which connect lakes) most commonly correspond with the features of small lowland rivers, whereas other canals and drainage ditches are filled with stagnant water with very poor clarity.

\title{
BIBLIOGRAPHY
}

1. Olejnik A.: 'Methodology of diagnosing surfaces of underwater objects with the application of visual systems"; Scientific Journal of Polish Naval Academy, Gdynia 2015, ISSN 0860-889X, e-ISSN 2300-5300, DOI: 10.5604/0860889X, Special issue 200A, p. 156,

2. Olejnik A.: An underwater object as a subject of technical diagnostics - basic issues”; Polish Hyperbaric Research No. 3(12) 2005, pp. 31-46, ISSN 1734-7009

Orzepkowski St.: „Underwater photography” Wyd. Naukowo Techniczne Warsaw, 1973

Teather R.G.: "Underwater investigations" Best Publishing Company USA 1995, ISBN 978-0941332262,

Williams J.: „Optical properties of the Sea” United States Naval Institute Series in Oceanography, USA, Annapolis, Maryland 1970, ISBN 0-87021-506-X

Wydro M.: „Rivers - underwater exploration in strong currents”; Polish Hyperbaric Research No. 1(22) 2008, pp. 31 - 40, ISSN 1734-7009.

\author{
dr inż. Adam Olejnik \\ Department of Underwater Works Technology in Gdynia, \\ Polish Naval Academy Poland \\ 81 - 103 Gdynia 3 \\ ul. Śmidowicza 69 \\ +586262746 \\ e-mail: a.olejnik@amw.gdynia.pl
}

